\title{
ORIGINAL ARTICLE \\ Developmental plasticity as a cohesive evolutionary process between sympatric alternate-year insect cohorts
}

\author{
PC Watts and DJ Thompson
}

Many species, particularly insects, pass through a series of distinct phases during their life history, with the developmental timing directed towards appropriate resources. Any factor that creates variation in developmental timing may partition a population into discrete populations-or 'cohorts'. Where there is continued failure to recruit outside the natal cohort then alternate cohorts will have their own internal dynamics, eventually leading to independent demographic and evolutionary trajectories. By contrast, continued variation in development rates within a cohort-cohort splitting-may homogenise otherwise independent demographic units. Using a panel of 14 microsatellite loci, we quantify the genetic signature of apparent demographic isolation between coexisting, but alternate, semivoltine cohorts of the damselfly Coenagrion mercuriale at locations that span its distribution in the UK. We find consistently low levels of genetic divergence between sympatric cohorts of C. mercuriale, indicative of developmental plasticity during the larval stage (unregulated development) whereby some individuals complete their development outside the predominant 2-year (semivoltine) period. Thus, individuals that alter their developmental rate successfully recruit to a different cohort. Despite maintaining contrasting population sizes, gene flow between alternate cohorts broadly is sufficient to place them on a similar evolutionary trajectory and also buffers against loss of genetic diversity. Such flexible larval development permits a response to local conditions and may facilitate response to environmental change.

Heredity (2012) 108, 236-241; doi:10.1038/hdy.2011.63; published online 27 July 2011

Keywords: coenagrion mercuriale; gene flow; larvae; life history; odonate; voltinism

\section{INTRODUCTION}

Species often undergo several discrete developmental phases as they progress through their life cycle, typically corresponding with seasonal changes or exploitation of particular habitats/resources. Understanding factors that regulate development not only provides insights into life history evolution, but also is crucial to comprehend the wider impacts of environmental changes: organisms capable of altering their developmental timing should cope better with novel or changing environments than those, which rely on intrinsic cues to regulate development. Any factor, such as a novel or changing environment, that creates variation in developmental timing may partition an apparent population into several distinct (that is, alternate) cohorts (Norling, 1984; Wolf and Zwick, 1989). Where individuals within a cohort maintain an ability to vary developmental rates-'cohort splitting'-then seemingly discrete cohorts can maintain some degree of demographic and/or genetic cohesion. By contrast, a fixed developmental period and/or failure to recruit outside the natal cohort will result in alternate cohorts having their own internal dynamics, leading to independent demographic and evolutionary trajectories.

Divergence between alternate cohorts with different phenologies (allochronic differentiation) potentially represents an effective isolating mechanism (Santos et al., 2007). Quantifying patterns of genetic divergence between alternate cohorts has received little attention, particularly for sympatric cohorts. For example, genetic differences between cohorts that may be indicative of reproductive isolation have been uncovered in some studies (Battisti et al., 2000; Santos et al., 2007), whereas the presence of genetic divergence at one location but not another suggests that there can be spatial component to the efficacy of temporal isolation (Coates et al., 2004). Conversely, weak or nonsignificant genetic differentiation among cohorts has been interpreted as evidence for gene flow between alternate cohorts (that is, developmental plasticity; Schultheis et al., 2002, 2008), but equally may arise because of insufficient time for genetic divergence (Marcon et al., 1999) or inadequate genetic marker resolution (Kankare et al., 2002). Beyond demonstrating a range of possible outcomes, it is hard to generalise about the efficacy of allochronic divergence as an isolating mechanism because, to our knowledge, no study has explicitly compared levels of genetic divergence between sympatric cohorts at more than just one or two study locations.

Odonates (dragonflies and damselflies) are a convenient model to study the consequences of developmental variation as this taxon displays inter- and intraspecific differences in voltinism (Corbet et al., 2006). Most odonates regulate their development by responding to extrinsic cues, principally photoperiod and temperature. Like many ectotherms, odonate growth rates are slower in colder environments (Flenner et al., 2010). Accordingly, odonates show latitudinal (corresponding with thermal) variation in voltinism, with most temperate species semivoltine or partivoltine (Corbet et al., 2006). Levels of intrapopulation cohort splitting and associated genetic patterns are poorly understood, however. 
Coenagrion mercuriale (Charpentier, 1840, Odonata: Zygoptera) is principally a Mediterranean species that exhibits geographic variation in developmental time. Most southern European populations are univoltine, possibly becoming bivoltine in Morocco. From midEurope to the northwest edge of its range in the UK, by contrast, C. mercuriale cannot complete development within a year and populations of this species are semivoltine (Purse and Thompson, 2002). Evidence for demographic isolation between alternate cohorts is provided by the large differences between cohorts in the maximum numbers of adults observed during surveys (Aylesbeare, SY054906, Figure 1; Kerry, 2001); similar observations have been noted elsewhere (Beaulieu Heath, New Forest; DK Jenkins, unpublished). There is a possibility that cohorts are, at least partially, reproductively isolated. Indeed, genetic differentiation between cohorts is expected as $C$. mercuriale is characterised by substantial spatial genetic structure (Watts et al., 2005, 2006, 2007); moreover, as the rate of loss of genetic diversity is determined by (effective) population size (Allendorf and Luikart, 2007), the even-year cohort may experience greater rates of genetic erosion. Contrary to these expectations, Watts et al. (2005) found little genetic divergence among alternate cohorts, but these conclusions are limited because comparisons between cohorts were made at just one site. Because of population decline and fragmentation, C. mercuriale is protected throughout Europe (Thompson et al., 2003). As such, gaining a deeper understanding of the level of isolation between alternate cohorts over a broad range of sympatric sites is an essential part of this species' conservation and genetic management.

In this paper we quantify the level of genetic differentiation between temporally discrete cohorts of C. mercuriale that are distributed throughout most of this species' UK distribution to determine the potential for sympatric divergence. These data have implications for the conservation management of this species and the role of allochronic divergence among alternate cohorts in general.

\section{MATERIALS AND METHODS}

\section{Description of study sites and genotyping}

We collected a single tibia from sympatric cohorts (during 2002 and 2003) of C. mercuriale ( $n=33-52$ per site) at 9 locations that span its UK distribution. Two sites (Hatchet Stream and Shipton Bottom) are situated within C. mercuriale's population stronghold at Beaulieu Heath in the New Forest (see Watts et al., 2007), whereas the remaining areas (Acres Down, Stony Moors, Corfe East, Aylesbeare Common, Moortown Gidleigh Common, Dry Sandford

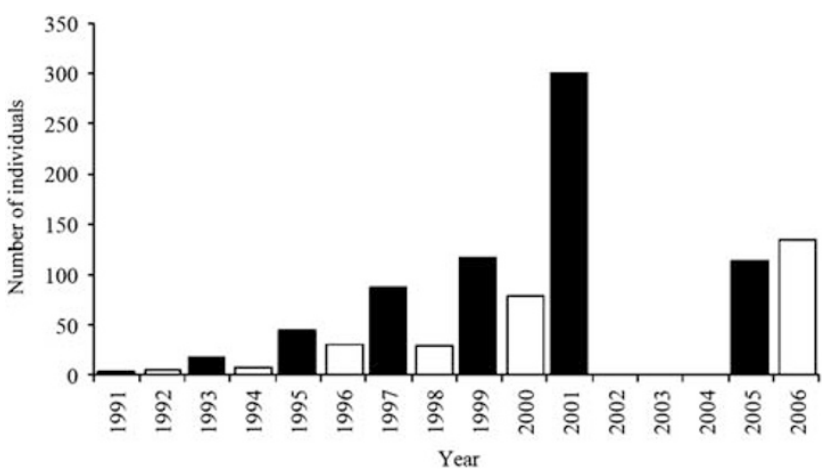

Figure 1 Variation in maximum annual counts between odd- (filled columns) and even- (open columns) year cohorts of the southern damselfly Coenagrion mercuriale along a transect at AYL in Figure 2. Note that the counts are comparable from 1994 when the transect was standardised along a specific route. All counts were made during warm, relatively calm days between 1200 and 1400 hours during which there was sunshine for at least $60 \%$ of the time (data provided by $L$ Kerry). and Nant Isaf) are smaller populations that are isolated by distance and inhospitable habitat from other C. mercuriale sites (Figure 2). Tibias were stored in $100 \%$ ethanol until DNA extraction. Full details of the protocols used for DNA extraction and genotyping have been described by Watts et al. (2004a, b). Every individual was genotyped at 14 unlinked microsatellite loci: LIST4-002, LIST4-024, LIST4-034, LIST4-037, LIST4-062, LIST4-063, LIST4023, LIST4-030, LIST4-031, LIST4-035, LIST4-042, LIST4-060, LIST4-066 and LIST4-067 characterised by (Watts et al., 2004a, b).

\section{Data analysis}

All individual samples were tested for departure from expected HardyWeinberg equilibrium conditions using the randomisation procedure $(5000$ permutations of alleles among individuals within samples) implemented by FSTAT version 2.9.3 (Goudet, 1995). The same software was used to calculate the basic measures of genetic diversity: allelic richness $\left(A_{\mathrm{R}}\right)$ standardised to 25 individuals, expected heterozygosity $\left(H_{\mathrm{e}}\right)$ and Wright's (1951) inbreeding coefficient $(f)$, and the level of differentiation between all pairs of samples (separate cohorts), genotypic differentiation and pairwise values of $F_{\mathrm{ST}}$ (Weir and Cockerham, 1984). Permutation tests (5000 permutations of samples among groups) were used to determine whether genetic diversity $\left(A_{\mathrm{R}}, H_{\mathrm{e}}\right.$ and $f$ ) and pairwise differentiation $\left(F_{\mathrm{ST}}\right)$ significantly differed between cohorts, and also whether values of $F_{\mathrm{ST}}$ were significantly different from zero (5000 permutations of genotypes among samples).

The broad pattern of spatial genetic structure was characterised by the strength of isolation by distance, as determined by a regression of genetic differentiation $\left(F_{\mathrm{ST}} /\left(1-F_{\mathrm{ST}}\right)\right)$ among pairs of populations from the same cohort against the ln-distances separating them (Rousset, 1997). The significance of any difference between the isolation by distance slopes that characterise each cohort was evaluated using a $t$-test. Analysis of molecular variance was used to partition the contribution to genetic diversity arising from spatial variation with that occurring between cohorts. The significance of the fixation indices were tested using the permutation procedure (10000 permutations) implemented by ARLEQUIN version 2.000 (Schneider et al., 2000).

EASYPOP version 2.0.1 (Balloux, 2001) was used to simulate the expected amount of genetic divergence $\left(F_{\mathrm{ST}}\right)$ that would develop between pairs of populations under different rates of migration. Briefly, we simulated genotypes

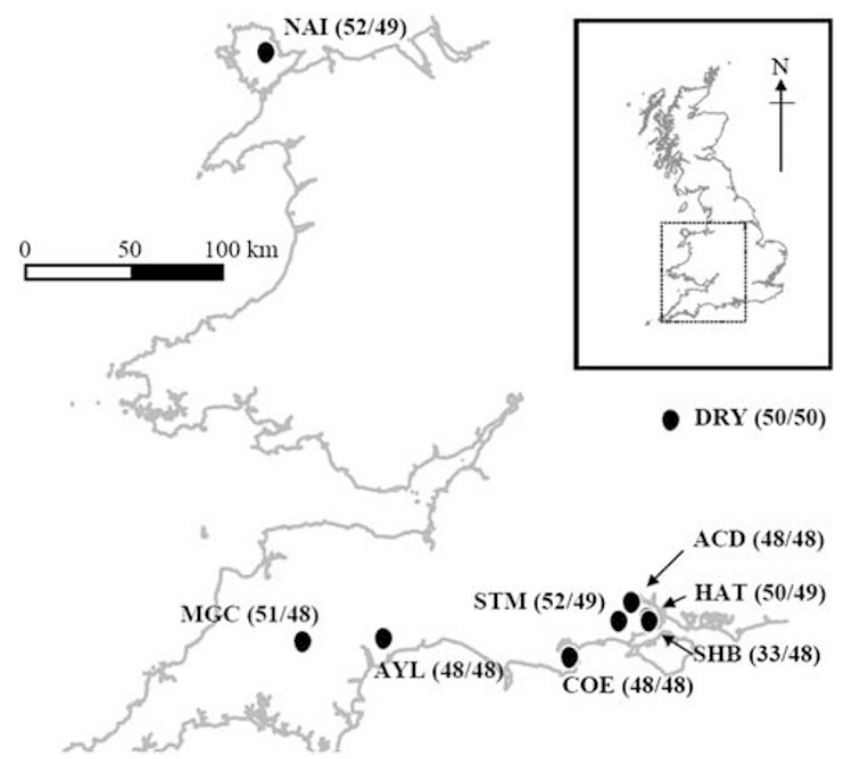

Figure 2 Sample locations of C. mercuriale in south-west England and Wales (UK), with sample sizes of the 2002 and 2003 alternate-year cohorts provided in parentheses. Dashed line in inset indicates the position of the sample locations in relation to Great Britain. ACD, Acres Down; AYL, Aylesbeare Common; COE, Corfe East; DRS, Dry Sandford; HAT, Hatchet stream; MGC, Moortown Gidleigh Common; NAI, Nant Isaf; SHB, Shipton Bottom; STM, Stony Moors. 
for 500 generations in two random mating populations with genetic properties similar to our data set (that is, diploid species with equal numbers of males and females, 14 loci with 5-20 alleles, mutation rate of 0.0001 and stepwise model of mutation) and then calculated the final pairwise $F_{\text {ST }}$. Migration rates were varied between 0 and 0.15 . The simulations were performed for an effective population size of 100 (typical of C. mercuriale populations, Watts et al., 2007) and 1000 (an order of magnitude increase that should dampen the rate of genetic differentiation).

Finally, 2MOD was used to implement a Markov chain Monte Carlo coalescent modelling procedure (Ciofi et al., 1999) to calculate the relative likelihoods of two contrasting models of demographic history: (1) populations at immigration-drift equilibrium (gene flow between populations) or (2) a non-equilibrium model of population separation, with drift and no gene flow. The Markov chain Monte Carlo simulations were run twice (on separate PCs) for each sympatric pair of cohorts for 20000 iterations. Model probabilities were calculated from the proportions of indicator variables that inform on the most likely model during each iteration, with the output from the first $10 \%$ of iterations discarded to prevent dependence on initial values. This modelling procedure was used also to calculate population-specific F-coefficients (the probability that two genes share a common ancestor within a population).

\section{RESULTS}

Sixteen of the sample-locus combinations were monomorphic: LIST4-037 and LIST4-062 for both cohorts at Aylesbeare Common, LIST4-024, LIST4-030, LIST4-031 and LIST4-067 for both Nant Isaf cohorts, LIST4-023, LIST4-034, LIST4-63 for the Nant Isaf (2003) cohort, and LIST4-002 for Nant Isaf (2002) only. Most of the 236 (polymorphic) sample-locus combinations significantly met expected Hardy-Weinberg equilibrium conditions $(P>0.05$ corrected for $k=7-14$ multiple tests per sample): the exceptions were LIST4-060, LIST4-066 and LIST4-031 with 5, 3 and 1 samples having an excess of heterozygotes, respectively (data not shown).

No significant differences in the level of genetic variation or population differentiation were observed between groups of samples in separate cohorts $\left(A_{\mathrm{R}}=3.16,3.16, P=0.994 ; H_{\mathrm{e}}=0.44,0.45\right.$, $P=0.982 ; f=0.01,0.00, P=0.503 ; F_{\mathrm{ST}}=0.24,0.22, P=0.831$; values presented for 2002, 2003 cohorts, respectively). As expected from previous work on this species (Watts et al., 2005, 2006, 2007), values of $F_{\mathrm{ST}}$ and genotypic differentiation among sites were generally high, with most values of pairwise $F_{\mathrm{ST}}>0.15$, and significantly $(P<0.05)$ different, with the exception of contrasts between samples (Hatchet stream and Shipton Bottom) from Beaulieu Heath (Supplementary Information 1). The majority (6 out of 9 tests) of the sympatric cohorts did not display significant genotypic differentiation; similarly, values of $F_{\mathrm{ST}}$ among sympatric cohorts were generally low (average $F_{\mathrm{ST}}=0.014$, range $0.006-0.026$ ), although these differences were significant for all but three pairwise comparisons (Supplementary Information). Concordant with these results, analysis of molecular variance reveals significant $(P<0.001)$ genetic variation among populations from the same cohort (that is, significant spatial genetic structure) and within populations themselves, but not between sympatric, alternate cohorts (Table 1 ).

A significant pattern of isolation by distance genetic structure was observed during both $2002\left(y=0.146 x-1.326, R^{2}=0.401, P<0.0001\right)$ and $2003\left(y=0.149 x-1.356, R^{2}=0.412, P<0.0001\right)$ cohorts. This isolation by distance pattern is similar for both cohorts (Figure 3), with no significant difference between gradients $(P>0.05, t=0.928$, $d f=140$ ); indeed, the regression of pairwise values of $F_{\mathrm{ST}}$ between equivalent pairs of populations from each cohort was highly significant, with a slope of 1 and intercept of $0 \quad\left(y=1.003 x, R^{2}=0.985\right.$, $P<0.0001)$ that indicated almost no difference between the two cohorts in their general pattern of spatial genetic structure across the UK (see also Supplementary Information 2).
Table 1 Analysis of molecular variance (AMOVA) of alternate-year cohorts of the southern damselfly (Coenagrion mercuriale) from sample locations throughout from the UK, collected during 2002 and 2003

\begin{tabular}{|c|c|c|c|c|}
\hline Source of variation & $\begin{array}{c}\text { Variance } \\
\text { components }\end{array}$ & $\begin{array}{c}\% \\
\text { Variation }\end{array}$ & $\begin{array}{c}\text { Fixation } \\
\text { index }\end{array}$ & $P$ \\
\hline Among cohorts & -0.086 & -2.48 & -0.0248 & 0.9875 \\
\hline Among populations within cohorts & 0.804 & 23.11 & 0.2255 & $<0.0000$ \\
\hline Within populations & 2.760 & 79.39 & 0.2063 & $<0.0000$ \\
\hline
\end{tabular}

$P$, probability of a more extreme variance component than that observed.

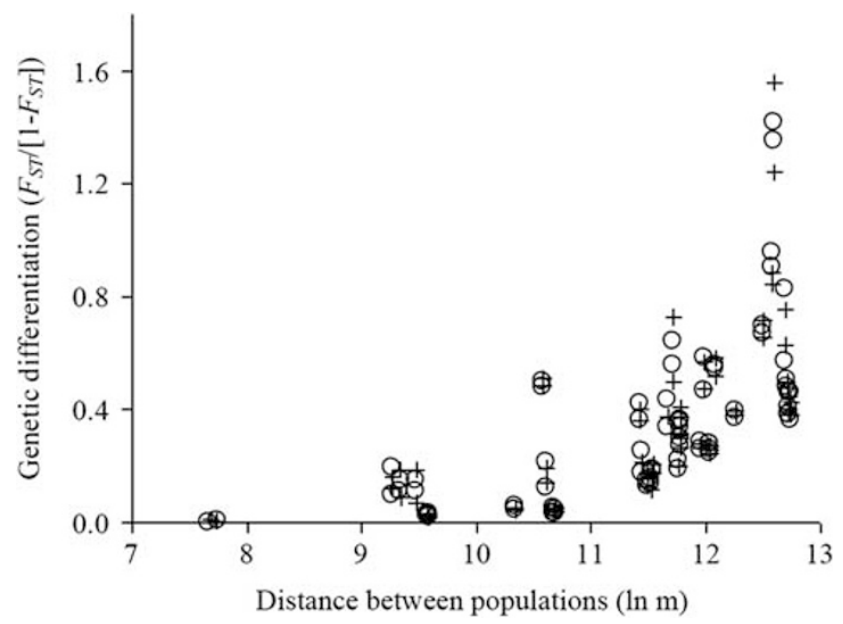

Figure 3 Isolation by distance pattern of genetic differentiation, represented by the relationship $\left(F_{\mathrm{ST}} /\left(1-F_{\mathrm{ST}}\right)\right)$ against the natural logarithm of the distance separating pairs of samples, for $C$. mercuriale in Great Britain during the 2002 (crosses) and 2003 (circles) alternate-year cohorts.

The results for separate runs of $2 \mathrm{MOD}$ were pooled because the overall outcomes of individual model runs were significantly correlated (Pearson's correlation, $R=0.813, P<0.001$ ). At most sites ( 7 out of 9) a model of migration-drift equilibrium (the gene flow model) was favoured over the non-equilibrium drift model, the exceptions being Stony Moors and Corfe East (Table 2). Population-specific values of $F$ were generally low $(\sim 0.01-0.03)$, but noticeably an order of magnitude higher $(F=0.15-0.19)$ for the cohorts at the isolated Nant Isaf site (Table 2).

\section{DISCUSSION}

Potential consequences of geographic variation in developmental timing have been considered widely (Blanckenhorn, 1991; Corbet et al., 2006; Winterhalter and Mousseau, 2007; Altermatt, 2010), but few studies have examined the genetic consequences of withinpopulation variation in developmental rates that generates alternate cohorts. We quantified the magnitude of genetic divergence between sympatric, alternate-year cohorts of $C$. mercuriale at nine locations that span this species' UK range to determine whether a consistent contrast in demography (Figure 1), which points towards separate cohort dynamics, corresponded with sympatric genetic divergence. Low levels of genetic differentiation between all pairs of sympatric cohorts is indicative of developmental plasticity whereby some individuals complete their development at a different rate to their natal cohort and successfully recruit to an alternate cohort. 
Table 2 Probabilities of two models of demographic history for nine sympatric alternate-year cohorts of the southern damselfly (Coenagrion mercuriale); values of $\boldsymbol{F}$ (the probability that two genes share a common ancestor) indicate the relative influence of gene flow and drift (low and high values, respectively)

\begin{tabular}{|c|c|c|c|c|c|}
\hline & \multicolumn{3}{|c|}{$\mathrm{P}$} & \multicolumn{2}{|c|}{$\mathrm{F}$} \\
\hline & Gene flow & Drift & Bayes factor & 2002 & 2003 \\
\hline$A C D$ & 0.761 & 0.239 & 3.19 & 0.012 & 0.023 \\
\hline HAT & 0.704 & 0.296 & 2.38 & 0.013 & 0.014 \\
\hline SHB & 0.753 & 0.247 & 3.05 & 0.014 & 0.005 \\
\hline STM & 0.379 & 0.621 & 0.61 & 0.009 & 0.006 \\
\hline $\mathrm{COE}$ & 0.475 & 0.525 & 0.90 & 0.005 & 0.030 \\
\hline AYL & 0.890 & 0.110 & 8.07 & 0.033 & 0.033 \\
\hline MGC & 0.833 & 0.167 & 4.97 & 0.027 & 0.031 \\
\hline DRY & 0.774 & 0.226 & 3.42 & 0.029 & 0.011 \\
\hline NAI & 0.540 & 0.460 & 1.17 & 0.149 & 0.188 \\
\hline
\end{tabular}

Abbreviations: ACD, Acres Down; AYL, Aylesbeare Common; COE, Corfe East; DRS, Dry Sandford; HAT, Hatchet stream; MGC, Moortown Gidleigh Common; NAI, Nant Isaf; SHB, Shipton Bottom; STM, Stony Moors.

Is the signal of temporal connectivity real or a historical artefact? Before interpreting values of $F_{\mathrm{ST}}$ as a measure of contemporary gene flow, potential confounding effects of shared ancestry and insufficient time for divergence must be considered. Demes that become isolated from an initial random-mating population will diverge genetically (measured by $F_{\mathrm{ST}}$ ) at a rate determined by the effective population size $\left(N_{\mathrm{e}}\right)$ and time $(t)$ since separation (specifically, $F_{\mathrm{ST}}=1-\left(1-\left(1 / 2 N_{\mathrm{e}}\right)\right)^{t}$, (Allendorf and Luikart, 2007)). Even though between 400 and 20000 adult damselflies occupy sites at this species' UK population stronghold (Beaulieu Heath), estimates of $N_{\mathrm{e}}$ are lower, typically varying from $\sim 60$ up to 235 (Watts et al., 2007). Using the latter value of $N_{\mathrm{e}}$ for C. mercuriale in the UK (most populations are smaller than those on Beaulieu Heath), the highest level of divergence between sympatric cohorts $\left(F_{\mathrm{ST}}=0.026\right.$, Supplementary Information 1$)$ would be achieved in just 12 generations ( 24 years): lower values of $F_{\mathrm{ST}}$ will be attained more rapidly.

Significant genetic differences between some cohorts (Supplementary Information 1) may represent partial reproductive isolation and/ or sampling error. The key issue here, however, is that $C$. mercuriale is typified by substantial genetic divergence throughout its UK range (Supplementary Information 1), and also over short $(<10 \mathrm{~km})$ distances (Watts et al., 2005). Species' spatial genetic structures inevitably reflect a complex footprint of colonisation and subsequent isolation. Even after an identical pattern of initial colonisation it is inconceivable that a matching pattern of divergence (Figure 3 ) could be achieved without connectivity between sympatric cohorts; the alternative scenario of an almost identical action of genetic drift (and selection, albeit at putative neutral loci) is implausible.

Finally, a model of migration drift (gene flow) generally is favoured over the alternative demographic scenario of isolation and subsequent divergence because of drift; also, in all but one instance the low values of $F$ (the probability of coalescence within populations) indicate a greater influence of immigration than genetic drift (Table 2). Consistent with these genetic lines evidence for flexible larval development and cohort splitting, C. mercuriale larvae respond to artificially warmed habitat by completing their development within a year (Thelen, 1992). Because C. mercuriale is at its northern range limit in the UK it is likely that unfavourable conditions (presumably low temperature) reduce growth rates, and therefore cohort splitting occurs when some larvae delay their development and mature after three years. Taken together, genetic and developmental evidence provide a convincing argument for widespread and contemporary gene flow between sympatric cohorts of $C$. mercuriale.

\section{Importance of cohort splitting from genetic and demographic standpoints}

Gene flow between cohorts is consistent with preliminary work on C. mercuriale (Watts et al., 2005) and some other insects (Schultheis et al., 2002, 2008); however, we are able to demonstrate that cohort splitting is geographically widespread and not restricted to a few, perhaps anomalous, populations. Crucially, this demonstrates the wider adaptive consequences of developmental plasticity-that a significant proportion of individuals who alter their developmental rate subsequently reproduce. Moreover, while sympatric, alternate cohorts may not be panmictic, the level of connectivity between cohorts is sufficient to minimise any potential 'cohort effect' to the overall pattern of spatial genetic structure (Table 1; Figure 3). This somewhat simplifies conservation management as the presence of genetically distinct sympatric populations would introduce an additional layer of complexity when designating appropriate units for conservation (see Hey et al., 2003). Indeed, while some work has presented evidence for a heritable component in developmental rate, apparently in response to local conditions (Blanckenhorn, 1991), numerous other studies have identified mixed developmental periods (that is, cohort splitting) within populations of odonates (Norling, 1984; Flenner et al., 2010), other insect taxa (Wolf and Zwick, 1989; Winterhalter and Mousseau, 2007; Lieske and Zwick, 2008) and arachnids (Kiss and Samu, 2005). In addition, laboratory rearing of several odonate species has provided support for developmental plasticity, rather than local adaptation (Flenner et al., 2010). Combined with our genetic data, such studies reinforce the idea that developmental plasticity in arthropods can be commonplace, certainly during the larval stages of odonates.

Given that cohort splitting appears to be a common feature of many insect populations, instances of temporally stable differences in flight patterns (that is, population abundance) between cohorts (for example, Kankare et al., 2002), reported for C. mercuriale (Figure 1; and Kerry 2001), are interesting. Because all sites (with the exception of Shipton Bottom and possibly Hatchet stream) are isolated from other C. mercuriale patches, the amount of inter-cohort genetic differentiation should reflect the level of cohort splitting per se rather than being confounded by immigration from allopatric cohorts. Statistical techniques to estimate rates of immigration $(m)$ tend to perform poorly when population structure is weak, often overestimating $m$ (Watts et al., 2007). However, some indication of the order of magnitude of the number of effective migrants (the product $N_{\mathrm{e}} m$ ) may be made from values of $F_{\mathrm{ST}}$ and Wright's (1951) approximation $F_{\mathrm{ST}} \sim 1 /\left(4 N_{\mathrm{e}} m+1\right)$; while there are well-documented problems associated with this approach (Whitlock and McCauley, 1999), our data indicate that roughly 9-40 effective migrants are exchanged between sympatric cohorts. These estimates are comparable with our simulated data. For effective population sizes $\left(N_{\mathrm{e}}\right)$ of 100 and 1000 then an average pairwise $F_{\mathrm{ST}}=0.014$ is expected with migration rates $(m)$ of 0.03 and 0.005 , respectively (that is, $N_{\mathrm{e}} m=3-5$ ); of course, lower and higher rates of migration are expected where populations have greater or less genetic differentiation, respectively (Table 3 ). Even accounting for the fact that estimates of $N_{\mathrm{e}}$ typically are less than the numbers of adults present $\left(N_{\mathrm{e}} / N\right.$ ratios of $\sim 0.1-0.4$ appear typical for this species Watts et al., 2007), this level of cohort splitting (some tens of 
Table 3 Simulated values of genetic differentiation $\left(F_{\mathrm{st}} \pm 95 \%\right.$ confidence intervals $(\mathrm{Cls})$ ) between pairs of populations with contrasting effective population sizes and with different rates of migration $(m)$

\begin{tabular}{cccc}
\hline$N_{\mathrm{e}}$ & $m$ & $\mathrm{~F}_{s t}$ & $95 \% \mathrm{Cl}$ \\
\hline 100 & 0.000 & 0.813 & 0.029 \\
& 0.001 & 0.433 & 0.078 \\
& 0.010 & 0.078 & 0.019 \\
& 0.030 & 0.015 & 0.006 \\
& 0.100 & 0.005 & 0.002 \\
& 0.150 & 0.001 & 0.002 \\
1000 & & & \\
& 0.000 & 0.124 & 0.008 \\
& 0.001 & 0.053 & 0.015 \\
& 0.005 & 0.012 & 0.002 \\
& 0.010 & 0.007 & 0.000 \\
\hline
\end{tabular}

individuals) appears insufficient to homogenise population demographics.

For reasons mentioned in the Introduction, the smaller, even-year C. mercuriale cohorts should lose genetic diversity faster than odd-year cohorts, but no significant differences in gene diversity between cohorts were uncovered. One obvious explanation for this is that gene flow between cohorts mitigates against loss of alleles. In addition, smaller populations may have larger $N_{\mathrm{e}} / N$ ratios than do larger ones (Watts et al., 2007), further buffering against genetic erosion. Thus, another consequence of flexible larval developmental timing is a potential safeguard against genetic erosion, which may be particularly important when adult reproductive success is severely limited during one season.

\section{Wider implications of developmental variation}

Environmental change is impacting on the geographic ranges and developmental timing of many species (Hassall et al., 2007; Altermatt, 2010), with the specific consequences determined by the level of intrinsic and extrinsic developmental regulation. Particularly with respect to levels of voltinism and cohort splitting, a key issue is to understand the factors that determine variation in the rate of development, both among and within populations. For example, odonate growth rate is influenced by temperature (Flenner et al., 2010), evident in many species as a latitudinal gradient in voltinism (Corbet et al., 2006). The limited latitudinal gradient represented by our study sites prevents a statistically meaningful assessment of any relationship between the level of cohort splitting (that is, migration among cohorts estimated from values of $F_{\mathrm{ST}}$ ) and latitude. Nevertheless, the largest genetic differences between cohorts were present at the most northerly and isolated site, Nant Isaf, which implies a possible greater effect of drift at the extreme range margin. Equally important considerations, however, include the manifold processes that affect larval developmental rates, and thus the level of cohort splitting, such as density of conspecifics (Banks and Thompson, 1987; Lieske and Zwick, 2008), predation (Johansson et al., 2001) and availability of food. The extent that intrapopulation variation in development rates (cohort splitting) is driven by microhabitat characteristics has key fitness implications and warrants further study.

A plausible model for species with flexible (unregulated) development, therefore, is an internal condition index that dictates whether completion of development is possible, with the timing of maturity modified by external cues to maximise fitness (see also Bradford and Roff, 1995; Flenner et al., 2010). Possible adaptive benefits associated with variation in developmental timing include reduced competition between siblings and reduced risk of failure of an entire brood (Norling, 1984; Bradford and Roff, 1995; Kiss and Samu, 2005). Developmental regulation in odonates, and indeed many other insect species, is important as often they are vulnerable to time constraints (such as the onset of winter in temperate environments). A typical response by many organisms that are approaching the end of a time constraint is accelerated development (Plaistow and SivaJothy, 1999; Johansson et al., 2001). Flexible larval development, however, permits the alternate response of delayed maturation (see also Bradford and Roff, 1995; Johansson et al., 2001; Winterhalter and Mousseau, 2007) that may overcome disadvantages associated with emerging late in a reproductive season, such as low mate densities and smaller offspring (with concomitant reduced competitive ability and increased susceptibility to predation/cannibalism). While delaying development increases the risk of pre-reproductive mortality (note that in one field survey we did not detect significant larval mortality over winter in an odonate; Banks and Thompson, 1987), this strategy ultimately may provide better mating opportunities as, after an extra period for growth, individuals potentially will be larger/have greater energy reserves. As such, the 'decision' to accelerate or delay development clearly impacts on an individual's fitness, albeit in a somewhat unpredictable way, whereas cohort splitting within a brood provides putative benefits associated 'bet-hedging' to the parents (see also Kiss and Samu, 2005).

To conclude, genetic data indicate that sympatric, alternate cohorts of the odonate $C$. mercuriale are connected by gene flow that places them on a similar evolutionary trajectory and buffers against loss of genetic diversity. This presents two important issues for conservation. First, although the smaller cohorts are apparently susceptible to greater rates of genetic erosion, they do not require genetic augmentation as they naturally receive migrants from the sympatric, larger cohort. Second, if the adults from any cohort perform poorly (for example, have poor reproductive success due to bad weather) then the cohort will eventually recover because of immigration from the alternate cohort. Given the evidence for geographical variation in voltinism, the phenomenon of connectivity between alternate cohorts is likely widespread in odonates and indeed many other insect taxa perhaps depending upon their ecological requirements. Such developmental plasticity, manifest as multi-voltinism both throughout a species' range and also within sites, potentially overcomes the limitations associated with local adaptation or obligate developmental periods by facilitating a rapid response to variable environmental conditions at both local and regional scales, and is an important consideration when predicting the impacts of climate change.

\section{CONFLICT OF INTEREST}

The authors declare no conflict of interest.

\section{ACKNOWLEDGEMENTS}

C. mercuriale is protected under Schedule 5 of the Wildlife \& Countryside Act (1981). All work was carried out under licence from English Nature. We thank all the landowners for allowing us onto their land and are grateful to the NERC (NER/A/S/2000/01322), the Itchen Sustainability Study Group and the Environment Agency for provision of funds. We thank Tim Sykes, Alison Strange and all those involved in the CMR studies for their help and Leslie Kerry for survey data. 
Allendorf FW, Luikart G (2007). Conservation and the Genetics of Populations. Blackwell Publishing: Oxford.

Altermatt F (2010). Climatic warming increases voltinism in European butterflies and moths. Proc Roy Soc B 277: 1281-1287.

Balloux $F$ (2001). EASYPOP (version 1.7): a computer program for population genetics simulations. J Heredity 92: 301-302.

Banks MJ, Thompson DJ (1987). Regulation of damselfly populations-the effects of larval density on larval survival, development rate and size in the field. Fresh Biol 17: 357-365.

Battisti A, Boato A, Masutti $L$ (2000). Influence of silvicultural practices and population genetics on management of the spruce sawfly Cephalcia arvensis. Forest Ecol Manag 128: 159-166.

Blanckenhorn WU (1991). Life-history differences in adjacent water strider populationsphenotypic plasticity or heritable responses to stream temperature. Evolution 45: 1520-1525.

Bradford MJ, Roff DA (1995). Genetic and phenotypic sources of life-history variation along a cline in voltionism in the cricket Allonemobius socius. Oecologia 103: 319-326.

Ciofi C, Beaumont MA, Swingland IR, Bruford MW (1999). Genetic divergence and units for conservation in the Komodo dragon Varanus komodoensis. Proc Roy Soc Lond B 266: 2269-2274.

Coates BS, Sumerford DV, Hellmich RL (2004). Geographic and voltinism differentiation among North American Ostrinia nubilalis (European corn borer) mitochondrial cytochrome $c$ oxidase haplotypes. J Insect Sci 4: 35.

Corbet PS, Suhling F, Soenderath D (2006). Voltinism of Odonata: a review. Int J Odonat 9: $1-44$.

Flenner I, Richter O, Suhling F (2010). Rising temperature and development in dragonfly populations at different latitudes. Fresh Biol 55: 397-410.

Goudet J (1995). FSTAT, Version 1.2: a computer program to calculate $F$-statistics. J Hered 86: 485-486.

Hassall C, Thompson DJ, French GC, Harvey IF (2007). Historical changes in the phenology of British Odonata are related to climate. Global Change Biol 13: 933-941.

Hey J, Waples RS, Arnold ML, Butlin RK, Harrison RG (2003). Understanding and confronting species uncertainty in biology and conservation. Tre Ecol Evol 18: 597-603.

Johansson F, Stoks R, Rowe L, De Block M (2001). Life history plasticity in a damselfly: effects of combined time and biotic constraints. Ecology 82: 1857-1869.

Kankare M, Varkonyi G, Saccheri IJ (2002). Genetic differentiation between alternate-year cohorts of Xestia tecta (Lepidoptera, Noctuidae) in Finnish Lapland. Hereditas 136: $169-176$.

Kerry L (2001). Habitat management for the Southern Damselfly Coenagrion mercuriale (Charpentier) on Aylesbeare Common, Devon. J Br Dragonfly Ass 17: 45-48.

Kiss B, Samu F (2005). Life history adaptation to changeable agricultural habitats: Developmental plasticity leads to cohort splitting in an agrobiont wolf spider. Environ Entomol 34: 619-626.

Lieske R, Zwick P (2008). Effects of intraspecific competition on the life cycle of the stonefly, Nemurella pictetii (Plecoptera: Nemouridae). BMC Ecol 8: 5.

Marcon PCRG, Taylor DB, Mason CE, Hellmich RL, Siegfried BD (1999). Genetic similarity among pheromone and voltinism races of Ostrinia nubilalis (Hubner) (Lepidoptera: Crambidae). Insect Mol Biol 8: 213-221.
Norling $U$ (1984). Life-history patterns in the northern expansion of dragonflies. AdvOdonatol 2: 127-156.

Plaistow S, Siva-Jothy MT (1999). The ontogenetic switch between odonate life history stages: effects on fitness when time and food are limited. Anim Behav 58 . 659-667.

Purse BV, Thompson DJ (2002). Voltinism and larval growth pattern in Coenagrion mercuriale (Odonata: Coenagrionidae) at its northern range margin. Eur J Entomol 99: $11-18$.

Rousset F (1997). Genetic differentiation and estimation of gene flow from F-statistics under isolation by distance. Genetics 145: 1219-1228.

Santos H, Rousselet J, Magnoux E, Paiva MR, Branco M, Kerdelhue C (2007). Genetic isolation through time: allochronic differentiation of a phenologically atypical population of the pine processionary moth. Proc Roy Soc Lond B 274: 935-941.

Schneider S, Roessli D, Excoffier L (2000). Arlequin version 2000, Genetics and Biometry. University of Geneva, Switzerland.

Schultheis AS, Booth JY, Vinson MR, Miller MP (2008). Genetic evidence for cohort splitting in the merovoltine stonefly Pteronarcys californica (Newport) in Blacksmith Fork, Utah. Aquat Insects 30: 187-195.

Schultheis AS, Hendricks AC, Weigt LA (2002). Genetic evidence for 'leaky' cohorts in the semivoltine stonefly Peltoperla tarteri (Plecoptera: Peltoperlidae). Fresh Biol 47. 367-376.

Thelen C (1992). Untersuchungen zum Larvenhabitat und Entwicklungszyklus der Helmazurjungfer (Coenagrion mercuriale, Zygoptera: Odonata) an zwei verschiedenen Gewässern der Freiburger Bucht. Diplomarbeit Fakt. Biologie, Limnol. Inst. Konstanz, AlbertLudwigs-Universität Freiburg, 160pp.

Thompson DJ, Rouquette JR, Purse BV (2003). Ecology of the Southern Damselfly. Conserving Natura 2000 Rivers Ecology Series No. 8. English Nature, Peterborough.

Watts PC, Kemp SJ, Saccheri IJ, Thompson DJ (2005). Conservation implications of genetic variation between spatially and temporally distinct colonies of the endangered damselfly Coenagrion mercuriale. Ecol Entomol 30: 541-547.

Watts PC, Saccheri IJ, Kemp SJ, Thompson DJ (2006). Population structure and the impact of regional and local habitat isolation upon levels of genetic diversity of the endangered damselfly Coenagrion mercuriale (Odonata: Zygoptera). Fresh Biol 51: 193-205.

Watts PC, Saccheri IJ, Kemp SJ, Thompson DJ (2007). Effective population sizes and migration rates in fragmented populations of an endangered insect (Coenagrion mercuriale: Odonata). J Anim Ecol 76: 790-800.

Watts PC, Thompson DJ, Kemp SJ (2004a). Cross-species amplification of microsatellite loci in some European zygopteran species (Odonata: Coenagrionidae). Int J Odonat 7: 87-96.

Watts PC, Wu JH, Westgarth C, Thompson DJ, Kemp SJ (2004b). A panel of microsatellite loci for the Southern Damselfly, Coenagrion mercuriale (Odonata: Coenagrionidae). Cons Genetics 5: 117-119.

Weir BS, Cockerham CC (1984). Estimating F-statistics for the analysis of population structure. Evolution 38: 1358-1370.

Whitlock MC, McCauley DE (1999). Indirect measures of gene flow and migration: $F_{S T} \neq 1$ / $(4 \mathrm{Nm}+1)$. Heredity 82: 117-125.

Winterhalter WE, Mousseau TA (2007). Patterns of phenotypic and genetic variation for the plasticity of diapause incidence. Evolution 61: 1520-1531.

Wolf B, Zwick P (1989). Plurimodal emergence and plurivoltinism of Central European populations of Nemurella pictetii (Plectoptera, Nemouridae). Oecologia 79: 431-438.

Wright S (1951). The genetical structure of populations. Ann Eugen 15: 323-354.

Supplementary Information accompanies the paper on Heredity website (http://www.nature.com/hdy) 